Journal of Advanced Research in Fluid Mechanics and Thermal Sciences

\title{
Computational Fluid Dynamics Study of a Modified Savonius Rotor Blade by Universal Consideration of Blade Shape Factor Concept
}

\author{
Abdel-Fattah Mahrous ${ }^{1,2, *}$ \\ 1 Mechanical Engineering Department, College of Engineering, Taif University, P.O. Box 888, Taif, Saudi Arabia \\ 2 Mechanical Power Engineering Department, Faculty of Engineering, Menoufia University, 32511, Shebin El-Kom, Egypt
}

\section{ARTICLE INFO $\quad$ ABSTRACT}

Article history:

Received 13 March 2021

Received in revised form 21 May 2021

Accepted 25 May 2021

Available online 27 July 2021

\section{Keywords:}

Wind energy; Savonius rotor; blade design; blade shape factor; CFD

\begin{abstract}
This work aims to investigate computationally the performance of Savonius vertical axis wind turbine having a new design feature for its blade geometry. The proposed design is based on a universal consideration of blade shape factor concept for the Savonius rotor blade. A blade shape factor ranges from zero to infinity, or vice versa, is considered in a single blade of the modified Savonius rotor. This means that each point in the two-dimensional blade profile of the suggested blade design has a single value of blade shape factor that is defined based on the dimensions of conventional semicircular blade. The computational results of the proposed blade shape design, having blade shape factor varying from infinity to zero, showed an improvement in Savonius turbine performance as compared to conventional blade shape design. Moreover, increasing the operating range of Savonius wind turbine is expected.
\end{abstract}

\section{Introduction}

The increasing consumption of non-renewable sources of energy as well as the environment legislation rules have urged researchers to look for alternatives that are in less impact on environment (environmentally friendly), cheaply available and satisfy the rising energy needs. Wind energy is considered as one of the available alternatives that is pollution free as well as available all hours of the day.

Power can be extracted from the wind with the use of wind turbines. According to the disposition of axis of rotation, there are two main types of wind turbines: namely, Horizontal Axis Wind Turbine (HAWT) and Vertical Axis Wind Turbine (VAWT). Beside the configuration, they vary in the way they extract energy from the wind. HAWTs entirely operate based on lift force, whereas VAWTs depend either on drag force or lift force to produce power. Despite its low efficiency, the VAWT's essential feature is that it captures wind from all directions and so there is no need to have yaw mechanism. The two main designs of VAWTs are Savonius and Darrieus rotors.

\footnotetext{
* Corresponding author.

E-mail address: afmahrous@yahoo.com
}

https://doi.org/10.37934/arfmts.85.1.2239 
Distinct features of Savonius rotors are simplicity in design, compactness, small noise levels, low vibration levels, low construction cost and potential to operate at low wind speed with higher torque [1]. A conventional Savonius rotor has two semi-circular blades attached to the opposite sides of a vertical shaft. The amount of wind power that can be harvested primarily depends on the configuration of rotor blades. The major problem associated with conventional Savonius rotor is the comparatively poor performance and thus research is definitely demanded for further enhancement [2].

Different attempts were made to investigate ways to enhance the power generated by Savonius rotor and consequently improve its performance. This was achieved either by adjusting turbine blade configurations such as twisting rotor blade and/or modifying blade profiles [3-12], by incorporating fixed shielding plates or deflectors [13-20] in the upstream side of the turbine rotor, by providing wind boosters or curtains to maximize wind strength around the entrance of the wind turbine [2124], or by altering the number of rotor blades, blade layers and/or the number of stages (multistacking) [1, 25-30].

Among others, Saha and Rajkumar [11] studied the effect of twisting rotor blades of a threebladed Savonius rotor on turbine performance. Investigation was done in a low-speed wind tunnel. The results showed the potential of twisted bladed rotor in terms of self-starting capability, increased efficiency, and smooth running as compared to those of a conventional semi-circular bladed rotor. Mohamed et al., [16] studied the effect of introducing an obstacle plate to partly shield the returning blade of two and three bladed Savonius rotor. It was concluded that installation of an obstacle plate improves self-starting capability and results in a considerable improvement in Savinous rotor performance at any angle of adjustment. Altan et al., [21] performed various experimental studies to investigate the effects of using curtains on the performance of Savonius wind turbine. In order to avoid the negative torque impacting on the convex blade surface of the Savonius wind turbine, they placed curtain arrangements in the front of the turbine rotor. They found that using curtains can improve turbine power coefficient of up to $38 \%$ depending on curtain angle. Wenehenubun et al., [28] investigated the influence of number of blades on the performance of Saconius wind turbine. Experiments compared the performance of two-, three- and four-blade Savonius wind turbines. Results showed that the three-bladed Savonius rotor exhibits higher rotational speed and has the best performance at high tip speed ratios. To investigate the effect of multi-stage on the performance of a Savonius rotor, computational simulation and experimental validation were conducted by Frikha et al., [25]. They tested five configurations differ in the number of stages. It was concluded that both torque and power coefficients are modified by increasing the number of stages. Mahrous [31] carried out a computational study to improve the performance of Savonius rotor by integrating both Savonius and Darrieus rotors in a single wind turbine design. The suggested design would work either as Savonius or Darrieus turbine depending on individual angles of rotor blades. The obtained computational results revealed that the performance of the suggested design could be controlled as well as optimized to cover the operating range of both designs of Savonius and Darrieus rotors.

In addition to twisting rotor blade, research was also done as an effort to improve Savonius wind turbine performance through modifications/optimization of turbine rotor blade design. Studied modifications include blade arc angle, blade shape factor and the entire blade geometry. Studies to optimize blade shape for maximum performance parameters were performed through references [2, 32-35]. Blade shape factor is defined as the ratio of blade arm length (p) to the radius of circular arc (q). Blade shape factor $(p / q)$ and blade arc angle $(\psi)$ are defined through Figure 1 [33], where D is the rotor diameter and $\mathrm{m}$ is the overlapping distance.

In continuation on seeking for a new approach to improve its performance, this work aims to investigate the performance of Savonius wind turbine with a modified rotor geometry. Modification 
made in the Savonius rotor is such that each point in the two-dimensional blade geometry is specified with a unique value of blade shape factor. This means that the points forming the profile of the rotor blade vary in coordinates according to the blade shape factor.

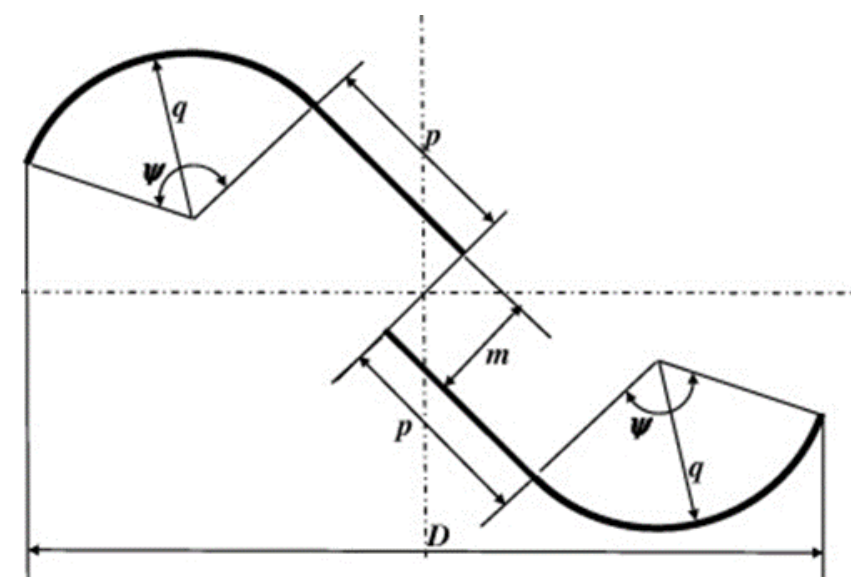

Fig. 1. Blade shape factor (p/q) and blade are angle $(\psi)$ of a modified Savonius rotor [33]

\section{Blade Shape Design Using Universal Blade Shape Factor Concept}

The proposed modified blade shape of Savonius wind turbine rotor is shown in Figure 2 along with both the conventional blade and individual blades with a definite blade shape factor each. The strategy used to get the set of points forming the blade shape of the proposed modified Savonius blade is explained in the current section.

The following variables and their range of variation are used in the analysis, see Figure 2.

$\mathrm{R}_{\mathrm{s}} \quad=$ Radius of semi-circular blade of the conventional rotor

$\mathrm{Q} \quad=$ Circular arc radius, where $0.0 \leq \mathrm{q} \leq \mathrm{R}_{\mathrm{s}}$

$c(a, 0)=$ Centre of circular arc, where $R_{s} \leq a \leq 2 R_{s}$ and $a+q=2 R_{s}$

Keeping the coordinates of the two end points $\mathrm{O}$ and $\mathrm{E}$ of the conventional blade unchanged, the coordinates of point of tangency $b(x, y)$ is found according to the following mathematical formulation. At the point of tangency $b(x, y)$, where the tangent (i.e., the blade arm) touches the circular arc circle, and therefore the equation of circle is satisfied.

Equation of circle forming the circular arc

$(x-a)^{2}+y^{2}=q^{2}$

Therefore

$x^{2}+y^{2}=q^{2}-a^{2}+2 a x$

Also at the point of tangency $b(x, y)$, since the blade arm is perpendicular to the radius of circular arc, therefore

Slope of blade arm $\times$ Slope of circular arc radius $=-1$ 
$\frac{y}{x} \times \frac{y}{(x-a)}=-1$

Thus

$x^{2}+y^{2}=a x$

Solving both Eq. (1) and Eq. (2) yields the coordinates of the point of tangency $b(x, y)$. This is

$x=\frac{a^{2}-q^{2}}{a}$

and

$y=\sqrt{-x(x-a)}$

The set of all pairs (x,y) defined according to Eq. (3) and Eq. (4) identifies the shape of Savonius modified Universal Blade (UB), see Figure 2.

The length of blade arm ( $p)$ is thus calculated from

$p=\sqrt{x^{2}+y^{2}}$

Local blade shape factor at the point of tangency is therefore defined as

Local blade shape factor $(L B S F)=p / q$

Local blade arc angle $(\psi)=180-\tan ^{-1}(p / q)$

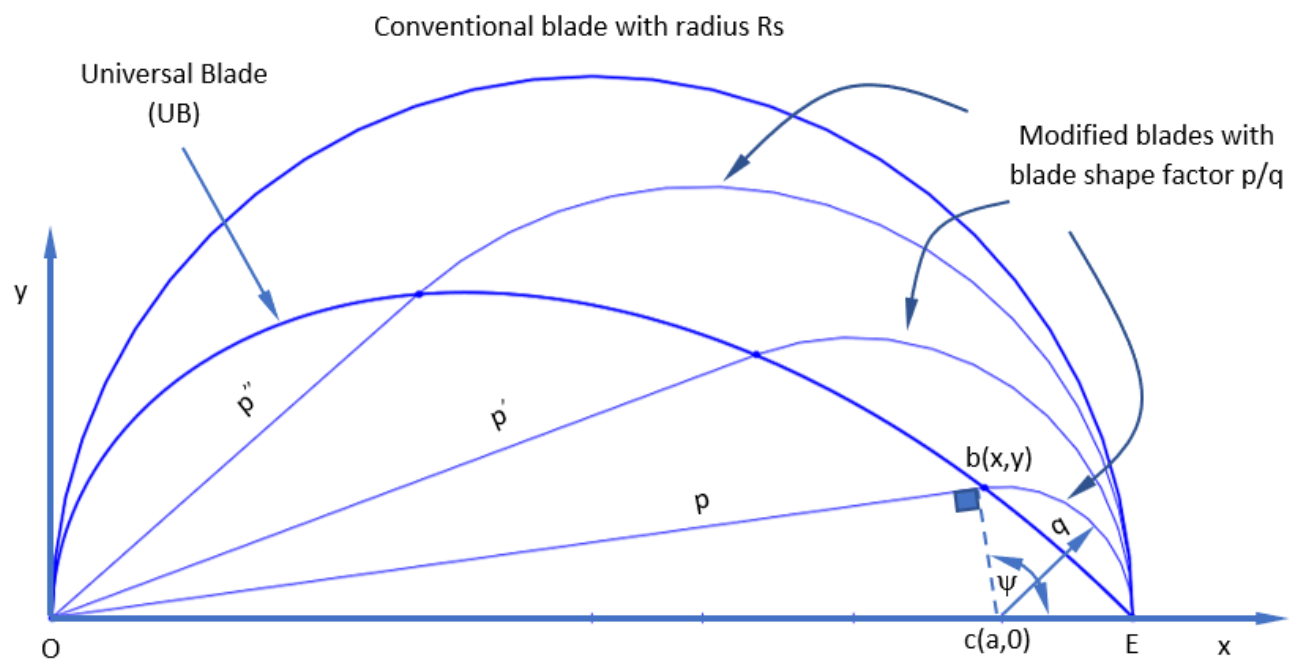

Fig. 2. Proposed modified blade shape of Savonius wind turbine rotor

According to the mathematical formulation mentioned so far, the set of all pairs $(x, y)$ can be found according to the following sequence. First, a value for circular arc radius $q$ is assumed according to the inequality: $0.0 \leq q \leq R_{s}$. Then, the $x$-coordinate of the center of circular arc is determined from a 
$=2 R_{s}-q$. After that, the $x$ and $y$ coordinates of the point of tangency $b(x, y)$ are obtained according to Eq. (3) and Eq. (4) respectively.

At the blade mean radius, the relation that can define the blade shape with universal consideration of blade shape factor (the UB blade) is obtained by fitting the set of points $(x, y)$ and written as:

$\dot{y}=-6.7466 \dot{x}^{6}+23.417 \dot{x}^{5}-32.45 \dot{x}^{4}+22.911 \dot{x}^{3}-9.4699 \dot{x}^{2}+2.2832 \dot{x}+0.0527$

With root-mean-squared value $R^{2}=0.9995$, where the dimensionless quantities $\dot{x}$ and $y$ are defined as

$\dot{x}=\frac{2 x}{D}$ and $\dot{y}=\frac{2 y}{D}$

where $D$ is the rotor diameter.

It has to be revealed that the blade shape factor $(p / q)$ for the obtained blade shape (i.e., UB) shown in Figure 2 varies from 0 to $\infty$, whereas it changes from $\infty$ to 0 when laterally inverting the geometry. The obtained universal blade shape factor (UB) blade geometry and the Laterally Inverted Universal Blade (LIUB) geometry are shown in Figure 3.

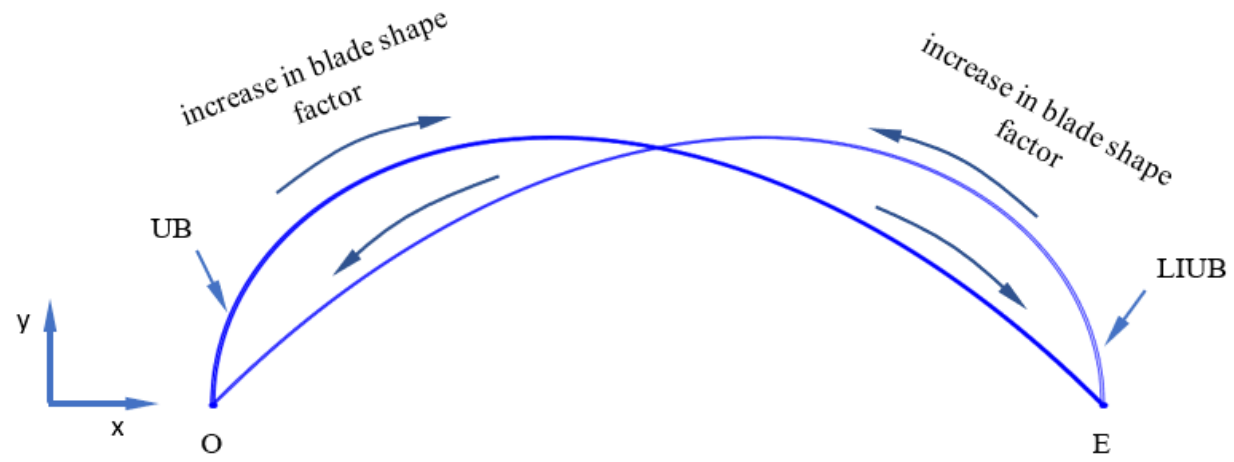

Fig. 3. Blade geometry with blade shape factor varies from 0 to $\infty$ (UB) and from $\infty$ to 0 (LIUB)

\section{Rotor Configurations under Investigation According to Blade Shape Factor}

The computationally investigated rotors according to blade shape factor are shown in Figure 4. In all investigated rotor configurations, the rotor diameter (D) is kept unchanged. However, the blade arc angle $(\psi)$ varies from rotor to another. Rotor 1 is the conventional/baseline rotor whereas rotors from Rotor 2 to Rotor 5 have a constant non-zero blade shape factor; blade shape factors respectively are $0.8,1.3,1.9$ and 2.8. Rotor 6 UB has the blade shape defined according to the coordinates of point of tangency $b(x, y)$ with blade shape factor varies from 0 to $\infty$. On the other hand, Rotor 6 LIUB is the laterally inverted rotor of Rotor 6 UB, i.e., blade shape factor varies from $\infty$ to 0 . In the current study, Rotor 6 LIUB has the target blade shape. 


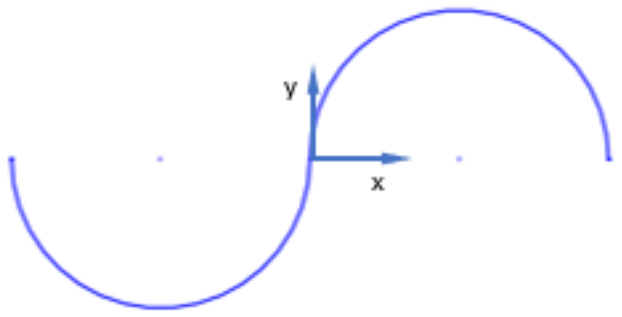

Rotor 1: Blade shape factor $=0.0$

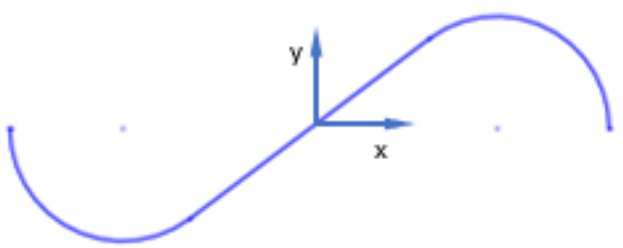

Rotor 3: Blade shape factor $=1.3$

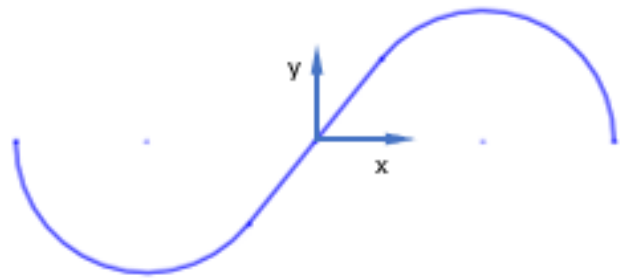

Rotor 2: Blade shape factor $=0.8$

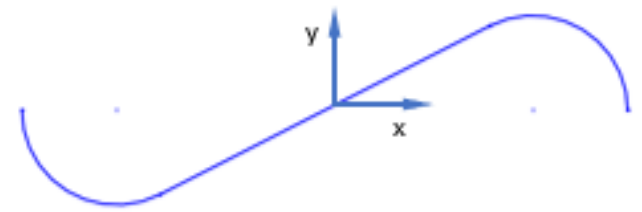

Rotor 4: Blade shape factor $=1.9$

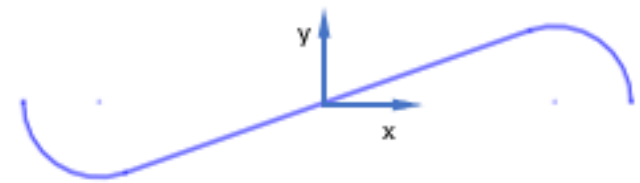

Rotor 5: Blade shape factor $(p / q)=2.8$

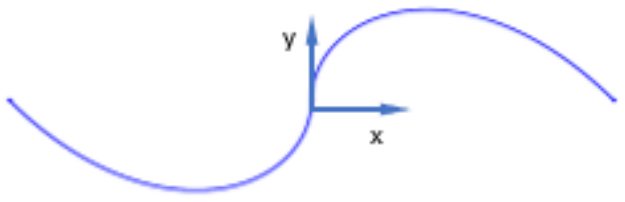

Rotor 6 UB: Universal blade

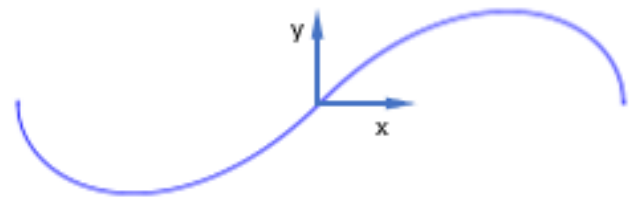

Rotor 6 LIUB: Laterally inverted universal blade

Fig. 4. Computationally investigated Savonius rotors according to blade shape factor

\section{Governing Equations, Computational Domain and Conditions}

The finite volume Computational Fluids Dynamics (CFD) solver, ANSYS Fluent 15, was used to study the performance of Savonius vertical axis wind turbine with different rotor designs. Mass and momentum conservation equations are the main governing equations of the air fluid flow over the turbine rotor. In the present study, the flow regime was turbulent, and the problem under consideration was solved in two-dimensional. The Reynolds-Averaged Navier-Stokes (RANS) equations are written in transient conditions as follows [31, 36].

Conservation of mass (Continuity equation)

$\frac{\partial \rho}{\partial t}+\frac{\partial}{\partial x_{j}}\left(\rho u_{j}\right)=0$

Conservation of momentum (Momentum equations)

$\frac{\partial}{\partial t}\left(\rho u_{j}\right)+\frac{\partial}{\partial x_{i}}\left(\rho u_{i} u_{j}\right)=-\frac{\partial P}{\partial x_{j}}+\rho g_{j}+\frac{\partial}{\partial x_{i}}\left[\mu\left(\frac{\partial u_{i}}{\partial x_{j}}+\frac{\partial u_{j}}{\partial x_{i}}\right)\right]+\frac{\partial}{\partial x_{i}}\left(-\rho \overline{u_{i}^{\prime} u_{j}^{\prime}}\right)$ 
where $\rho$ denotes the fluid density, $\mathrm{t}$ is the time, $u_{j}$ is the component of fluid velocity in the direction $\mathrm{j}, \mathrm{P}$ is the pressure, $\mathrm{g}$ is the gravitational acceleration, $\mu$ is the coefficient of viscosity and $x_{i}$ refers to spatial coordinate.

The last term in the momentum equation (Eq. (11)) denotes Reynolds's shear stress tensor and has to be properly modelled. The shear stress tensor is written using the concept of turbulent viscosity as

$-\rho \overline{u_{i}^{\prime} u_{j}^{\prime}}=\mu_{t}\left(\frac{\partial u_{i}}{\partial x_{j}}+\frac{\partial u_{j}}{\partial x_{i}}\right)$

In Eq. (12), the turbulent viscosity $\mu_{\mathrm{t}}$ is calculated using an appropriate turbulence model. In the current study, the Transition Shear-Stress Transport TSST (4 equations) turbulence model, variant of SST k- $\omega$ model, with default quantities was used to estimate the turbulent quantities. The SST k- $\omega$ model variants showed their ability to give acceptable results close to experimental data [37-41]. The TSST k- $\omega$ model is primary based on the SST model transport equations but coupled with two additional transport equations, one for intermittency and the other for the momentum thickness Reynolds number. The additional two transport equations can be found in reference [39].

The computational domain with the necessary boundary conditions is shown in Figure 5 . Based on available literature, the arbitrary selected dimensions of the turbine rotor are such that the diameter of the Savonius rotor (D) is $321.5 \mathrm{~mm}$. An upstream distance of 8D has been assigned before the turbine rotor, while a downstream distance of 25D has been set behind the rotor. The upper and lower planes were set at a distance of 8D each and are designated as symmetry boundary conditions. The computational domain was decomposed into two different fluid zones separated by interface boundaries: namely the rotating and stationary fluid zones. The rotating zone having a diameter of $2 \mathrm{D}$ has been set next to the rotor blades, while the remaining part of CFD domain was set as stationary zone.

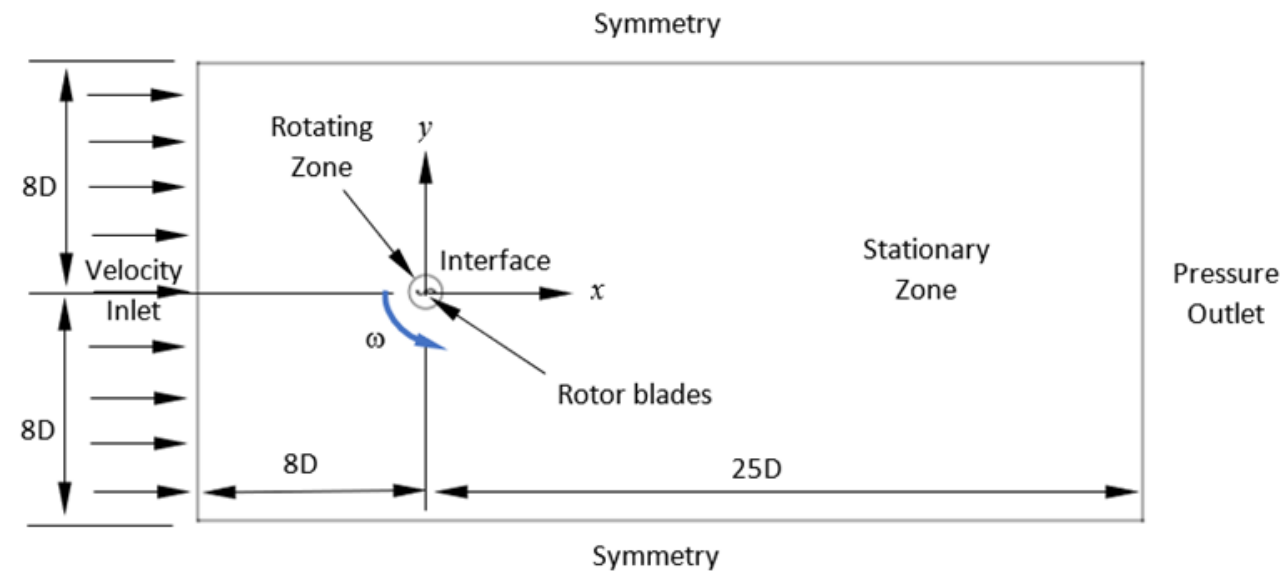

Fig. 5. 2-D Computational domain with various fluid zones and boundary conditions

The principle of sliding mesh in Ansys Fluent [36] was used to model the wind turbine rotating zone. Accordingly, the rotating zone (including turbine rotor) is able to rotate at various rotational speeds, whereas the rest of computational domain was kept stationary. At the inlet boundary of the computational domain, a uniform inlet fluid velocity of $8 \mathrm{~m} / \mathrm{sec}$ (wind speed) was imposed with a 5 
percent turbulence intensity. Besides, a pressure outlet boundary condition of one standard atmosphere was assigned at the outlet section.

The generation of the 2-D geometry wind turbine test models was done by using SolidWorks CAD software. The geometry was then imported into ANSYS Meshing and discretized to get the appropriate 2-D mesh. As an example of turbine rotor test model, Figure 6 shows the computational grid for the laterally inverted universal blade (LIUB) Savonius wind turbine. The rotating zone was discretized with triangular mesh, while a quad-tri hybrid mesh was chosen for the stationary zone. The growth rate of the main grid was set as 1.150 . Flow can hardly be affected by the wind turbine rotor in the far field region and therefore a coarser mesh was applied.

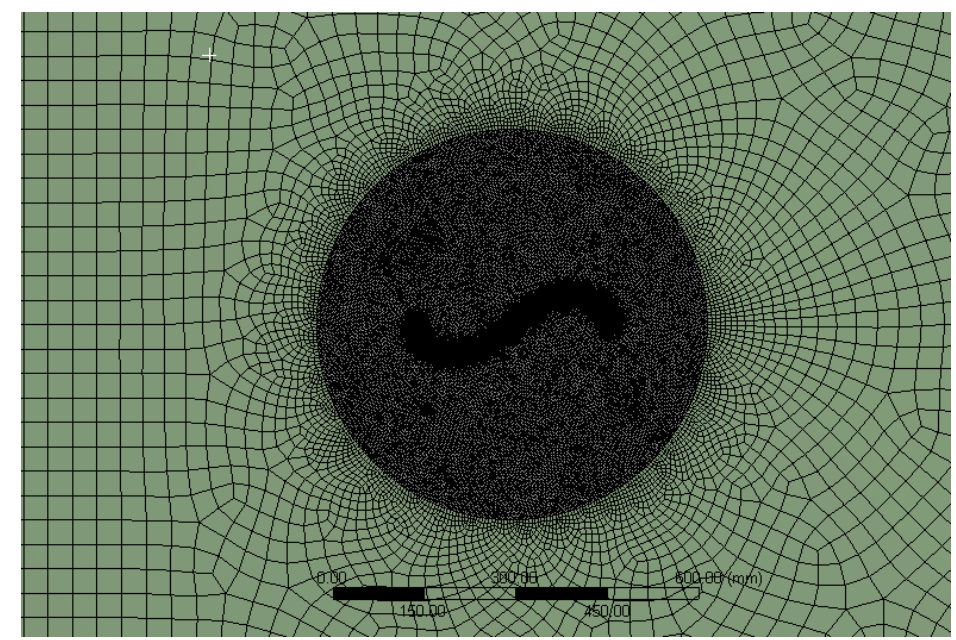

Fig. 6. 2-D Computational grid for the laterally inverted universal blade (LIUB) Savonius rotor

The rotor blades boundary mesh has to be fine enough to properly capture all physical effects within the rotating zone; particularly the pressure and shear forces that affect the calculation of rotor torque [37]. A closer view of the grid in the vicinity of the rotor blade is shown in Figure 7. Corresponding to a total depth of 0.0125D, eight boundary mesh inflation layers were created around rotor blades with a growth rate of 1.2. This helps in capturing the boundary layer region next to the blade.
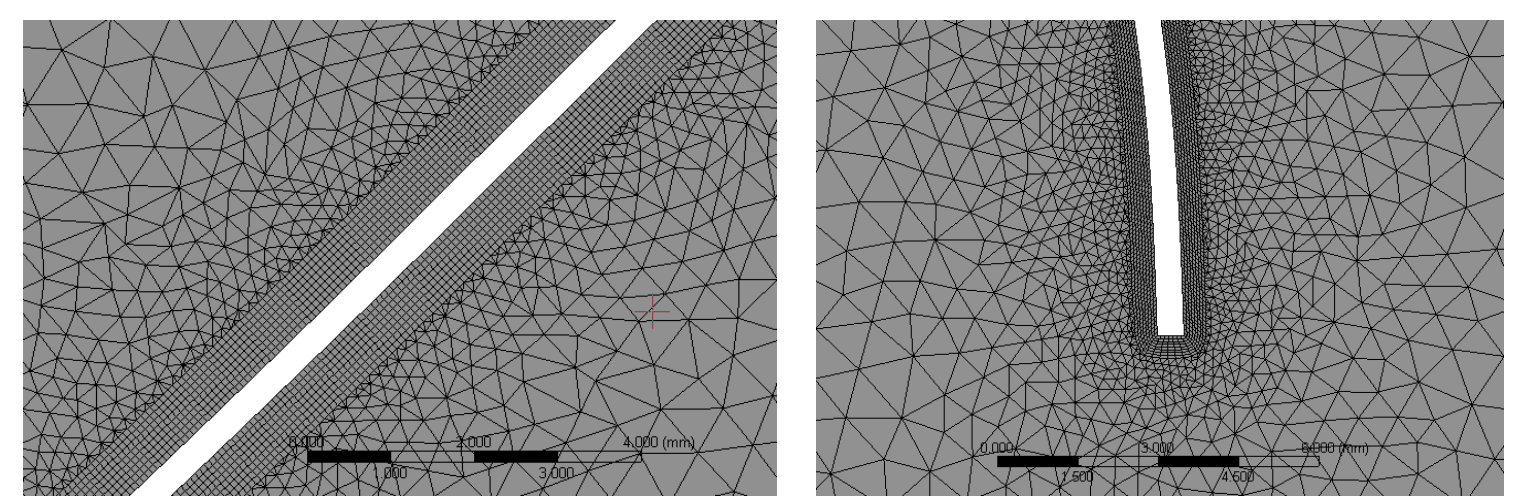

Fig. 7. Grid structure in the vicinity of LIUB rotor blade

The SIMPLE algorithm (Semi-Implicit Method) was chosen during the simulations to provide a better relationship between pressure and velocity. In this algorithm, a relationship between velocity and pressure corrections is used to implement mass conservation and to obtain the pressure field [36]. During the calculations and in conjunction with the double precision pressure-based algorithm, 
second order upwind spatial discretization in pressure, momentum and turbulence equations was employed along with a Least Squares Cell Based algorithm for gradients. The time step of transient calculations was set corresponding to a 10 of turbine rotor rotation at each turbine angular velocity $\omega$ (i.e., $\Delta t=\pi / 180 \omega$ ) [31]. It was reported in reference [35] that this value of time step provides an independent time step solution. With regards to solid walls, no-slip conditions for the velocity components along with zero normal pressure gradients were set as the boundary conditions. Additionally, smooth walls were designated for all solid walls. To judge for solution convergence, the simulations were given a solution convergence tolerance of $10^{-6}$.

\section{Performance Parameters of Wind Turbine}

The key role of rotor blades of the wind turbine is to transform the kinetic energy available in the wind stream into mechanical energy. The performance of the wind turbine is usually expressed in terms of torque and power coefficients. The power coefficient $\left(C_{p}\right)$ is defined as the ratio between the output mechanical power produced by the turbine rotor and the theoretical power available in the wind in the form of kinetic energy. This is written as

$C_{p}=\frac{P_{R}}{P_{W}}=\frac{2 \omega T}{\rho A_{s} V^{3}}$

where $P_{R}$ is the rotor generated power, $P_{W}$ is theoretical wind power, $\omega$ is the rotor angular velocity, $T$ is the torque produced by the turbine rotor, $\rho$ is the air density, $A_{s}$ is the rotor swept area of blades and $\mathrm{V}$ is the free stream wind speed.

The torque coefficient $\left(\mathrm{C}_{\mathrm{m}}\right)$ of wind turbine is calculated according to the following equation

$$
C_{m}=\frac{4 T}{\rho A_{s} V^{2} D}
$$

The tip speed ratio, $\lambda$, of the wind turbine is defined as the ratio of the rotor blade tip speed $(\omega D / 2)$ to the free stream wind speed $(\mathrm{V})$. This is

$$
\lambda=\frac{\omega D}{2 V}
$$

\section{Grid Independence Study of Laterally Inverted Universal Blade Turbine Rotor}

In order to ensure that the computational results are grid independent, grid independence tests were carried out for the laterally inverted universal blade shape factor (LIUB) wind turbine rotor. Conducted tests were performed separately on both stationary and rotating zones.

The stationary zone test was conducted such that the grid size for the rotating zone was kept unchanged while the gride size for the stationary zone was varied. Three different grides with different stationary zone mesh sizes were computationally tested. The total cell number for each one of the tested grids was 164835 (Grid 1s), 189186 (Grid 2s) and 289342 (Grid 3s), respectively. Figure 8 shows the spatial distribution of axial velocity and axial static pressure at rotor angle of 0.0 degrees. Even though the change in stationary zone mesh size, distributions of axial static pressure and axial velocity within the rotating zone area $(-2 \leq$ normalized axial distance $(x / D) \leq 2)$ are independent on stationary zone mesh size (i.e., do not significantly change). Although there is a change in the axial 
velocity distribution in the downstream region of turbine rotor, the axial velocity and axial static pressure within the rotating zone are not affected by this change. Besides, deviation in average value of torque coefficient while changing stationary zone mesh size was found very small, about $0.48 \%$ while changing stationary mesh size from Grid 1s to Grid 3s. Thus, the torque coefficient is believed independent on tested stationary zone mesh size. The stationary zone mesh size for Grid $2 \mathrm{~s}$ was subsequently used in the current study from the accuracy of results as well as CPU time point of views.

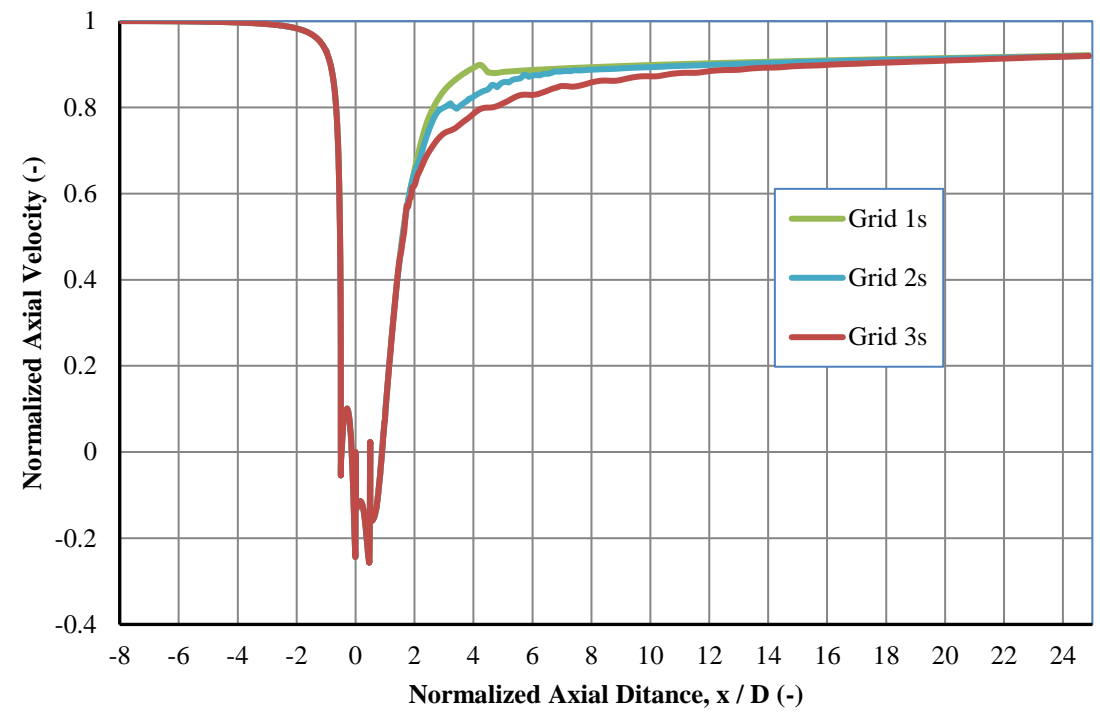

(a)

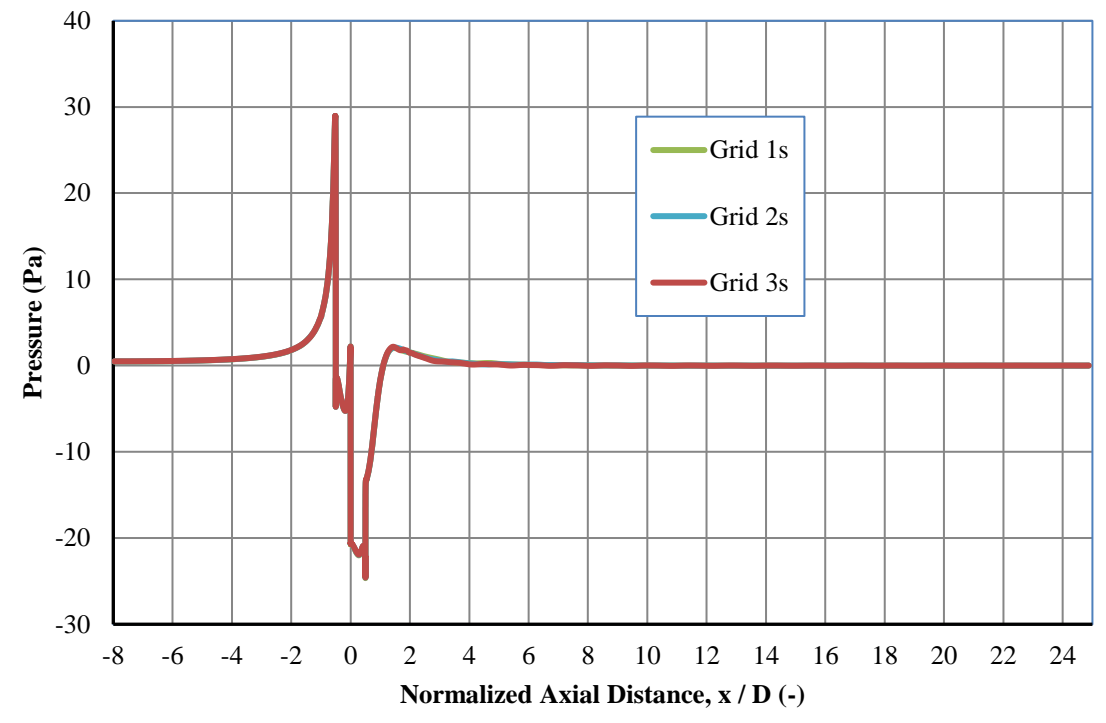

(b)

Fig. 8. Steady state spatial distribution of (a) axial velocity and (b) axial static pressure. Rotating zone is within the range of normalized axial distance from -2 to 2

Rotating zone grid independence tests were carried out by generating five different grids; differ only on rotating grid mesh size while keeping stationary zone mesh size at the size previously chosen. The total number of elements for each grid is 103370 (Grid 1), 146376 (Grid 2), 189186 (Grid 3), 232766 (Grid 4) and 267038 (Grid 5). Cyclic average power coefficient for the five different grids was compared through Figure 9. Results were obtained after seven complete revolutions of turbine rotor 
with a time step size corresponds to $\lambda$ of 0.7 (0.000501 sec). As shown in Figure 9 , the maximum discrepancy in computational $C_{p}$ from Grid 1 to Grid 5 is about $1.47 \%$. It is obvious from Figure 9 that the rotating zone with a mesh size corresponds to Grid 4 (total number of elements in the CFD domain = 232766; i.e., $125.18 \%$ increase in the number of elements with reference to Grid 1 ) gives a stable solution and can be used to save CPU time. Accordingly, mesh size for stationary and rotating zones of Grid 4 was employed in the current study.

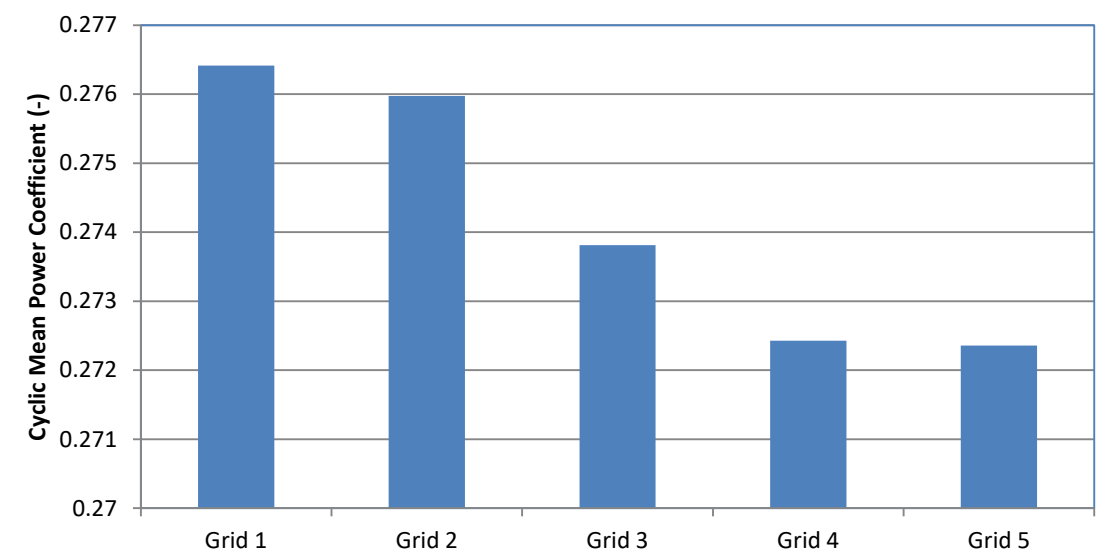

Fig. 9. Grid independence results at $\lambda=0.7$

\section{Results and Discussion}

The computational cyclic average torque and power coefficients for different rotor shapes are shown in Figure 10. The computational results were obtained after seven complete cycles of rotation and presented as variations of torque and power coefficients with respect to tip speed ratio for individual rotor design configurations. In the present research, the performance was assessed such that the conventional Savonius wind turbine with semi-circular blades (Rotor 1 ) is considered as the baseline model. As mentioned in Section 3, rotors being tested have blade shape factors $(p / q)$ of 0.0 (baseline case; Rotor 1), 0.8 (Rotor 2), 1.3 (Rotor 3), 1.9 (Rotor 4), 2.8 (Rotor 5), Universal blade with blade shape factor changes from 0 to $\infty$ (Rotor $6 \mathrm{UB}$ ) and laterally inverted universal blade with blade shape factor changes from $\infty$ to 0 (Rotor 6 LIUB).

As illustrated in Figure 10, the cyclic average torque and power coefficients are considerably affected by blade shape factor as compared to the baseline rotor design. As depicted, the UB rotor exhibits the worst performance with the lowest toque and power coefficients. Because of its distinct profile, the UB concave side holds its full capacity of air at shorter distances from the turbine centre of rotation. This results in a resultant air force acting at shorter arm length and consequently lower driving torque. On the other hand, the LIUB rotor shows a modified performance particularly at higher values of tip speed ratio, particularly at $\lambda>0.6$. This can be attributed to the larger arm length of the resultant drag force obtained when much air is held by the blade and the force is concentrated close to the tip edge. Blade design with a constant blade shape factor (rotors Rotor 2 to Rotor 5) commonly shows better performance than that for the conventional design. However, modifications in turbine performance at higher blade shape factor are not significantly high, as illustrated for Rotor 4 and Rotor 5 . Although increasing the blade shape factor tends to increase the arm distance of the resulting air force, the amount of air held by the blade bucket is reduced due to the decrease in blade arc radius. This makes the modification in turbine performance by further increasing the blade shape factor not so substantial. Blade design with laterally inverted universal blade shape factor (LIUB), on the other hand, has better performance with higher power coefficient than other blade shape 
factors. Unlike rotor performance with constant blade shape factor, the rotor design with laterally inverted universal blade shape factor (LIUB) shows an increasing trend of power coefficient near the end of the investigated range of tip speed ratio. This is expecting another peak on the $C_{p}$ performance curve (Figure 10(b)) with a higher power coefficient than illustrated. Besides, the results of blade design with universal consideration of blade shape factor (LIUB) expect running the turbine within a wide range of tip speed ratios. Accordingly, turbine rotor with laterally inverted universal blade shape factor is believed to have a potential to cover a wide range of performance parameters as well as to modify the turbine output power.

As shown in Figure 10(a), the highest torque coefficient is increased by about $48 \%$ in case of laterally inverted universal blade shape factor design LIUB as compared to the conventional rotor. In addition, the power coefficient is modified by about $62 \%$ at $\lambda=1.1$ when employing the laterally inverted universal blade shape factor design in relation to the conventional rotor. Furthermore, the range (i.e., maximum - minimum) of data variation for torque coefficient in case of laterally inverted universal blade shape factor (LIUB) is small as compared to corresponding variation of other designs of constant blade shape factors.

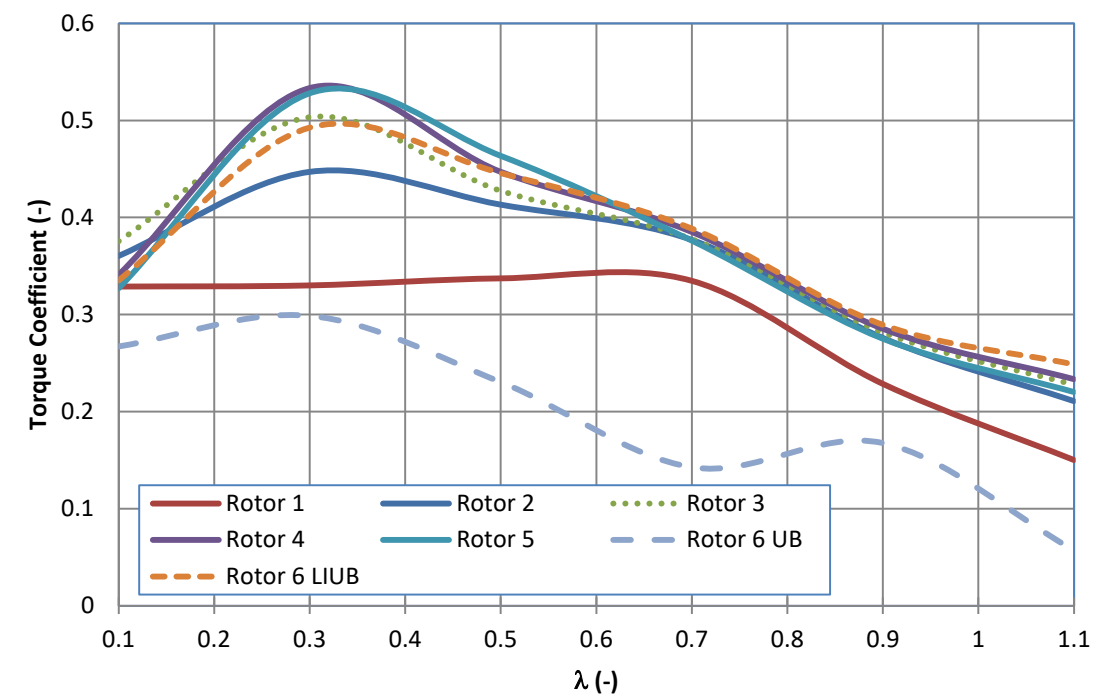

(a)

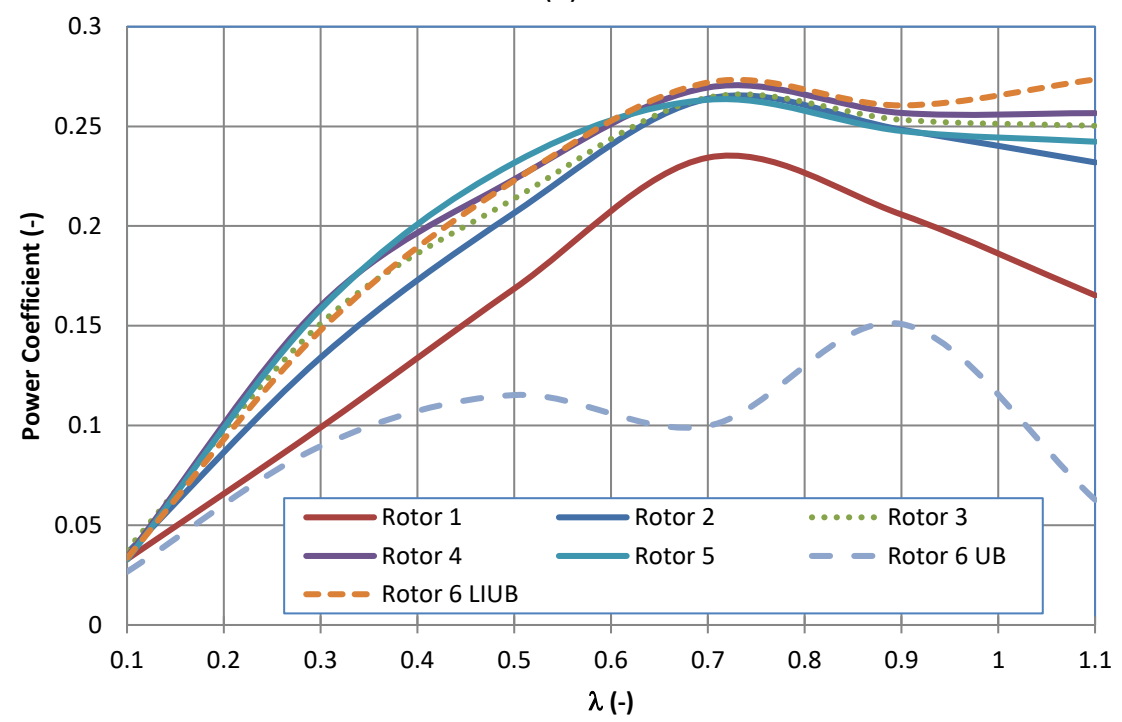

(b)

Fig. 10. Comparisons of cyclic average (a) torque and (b) power coefficients 
The temporal variations of torque coefficient for various rotor configurations are shown in Figure 11. Results are presented over one complete cycle of rotation at $\lambda=1.1$. It should be pointed out that positive values of torque coefficient mean that torques are produced in counter clockwise direction. Compared with the baseline rotor performance, a positive torque higher by $34 \%$ is produced by the laterally inverted universal blade shape factor design (Case 6 LIUB) at an angle of about $24 \mathrm{deg}$. The reason for such an increase may be attributed to the reduced drag force on the convex side of the returning blade because of decreased surface area of the laterally inverted universal blade shape factor design as compared to the conventional semi-circular blade. Accordingly, the rotor design with laterally inverted universal blade shape factor LIUB is driven by higher positive torque during the early angles of rotation than the conventional design. On the other hand, the laterally inverted universal blade shape factor design exhibits a larger negative torque (clockwise torque), but with less magnitude, at an angle of 113 deg. However, the resultant torque is positive and higher in case of laterally inverted universal blade shape factor design when compared with that of the baseline case. This demonstrates the reason for higher power coefficient in case of laterally inverted universal blade shape factor at $\lambda$ of 1.1 as illustrated in Figure 10(b).

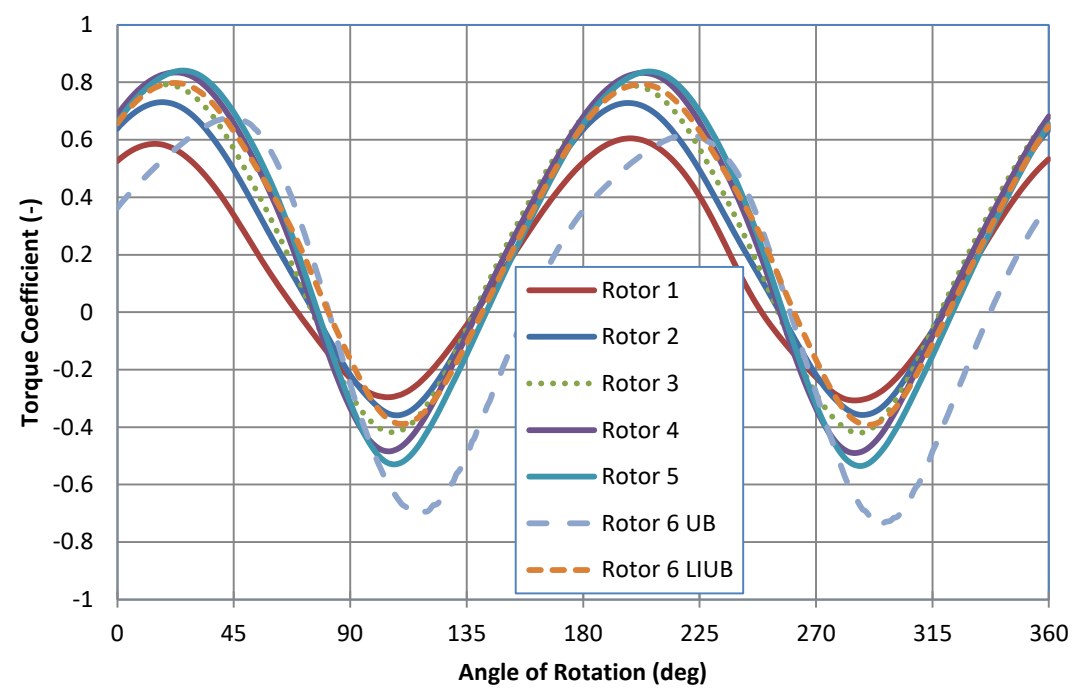

Fig. 11. Instantaneous torque coefficient for various rotor blade configurations at $\lambda=1.1$

The contours of static pressure at $\lambda=0.9$ were compared through Figure 12 for both the conventional blade and the laterally inverted universal blade shape factor (LIUB) designs. The contours were temporally displayed within the area of rotating zone at rotor angles of $0.0,45,90$ and 135 degrees. Highest pressure regions are coloured in red, while lowest pressure regions are coloured in blue. For both cases and within the displayed angles of rotation, the maximum pressure generally increases till rotor angle of 90 degrees and then decreases at the angle of 135 degrees. The laterally inverted universal blade shape factor exhibits an increase in static pressure of about $45 \mathrm{~Pa}$ when the angle of rotation reaches 90 degrees, as compared to $36 \mathrm{~Pa}$ in case of conventional rotor. It is clear from Figure 12 that the area of high pressure at 45 degrees angle of rotation is larger in case of laterally inverted universal blade shape factor than that in the case of conventional blade. The reason for such behaviour may be attributed to the geometric profile of each rotor configuration and its effect on variations of near wall local static pressure and velocity. Looking into the areas of low pressure, the laterally inverted universal blade shape factor blade always shows lower values of static pressure when compared to the conventional rotor case. A minimum value of $-455 \mathrm{~Pa}$ is reached at 
rotor angle of 90 degrees with the use of laterally inverted universal blade shape factor, while a minimum value of $-394 \mathrm{~Pa}$ is observed in case of conventional rotor at the same angle of rotation. The difference in static pressure in both sides of rotor blades, which is higher in case of laterally inverted universal blade shape factor, would result in higher torque and power coefficients.

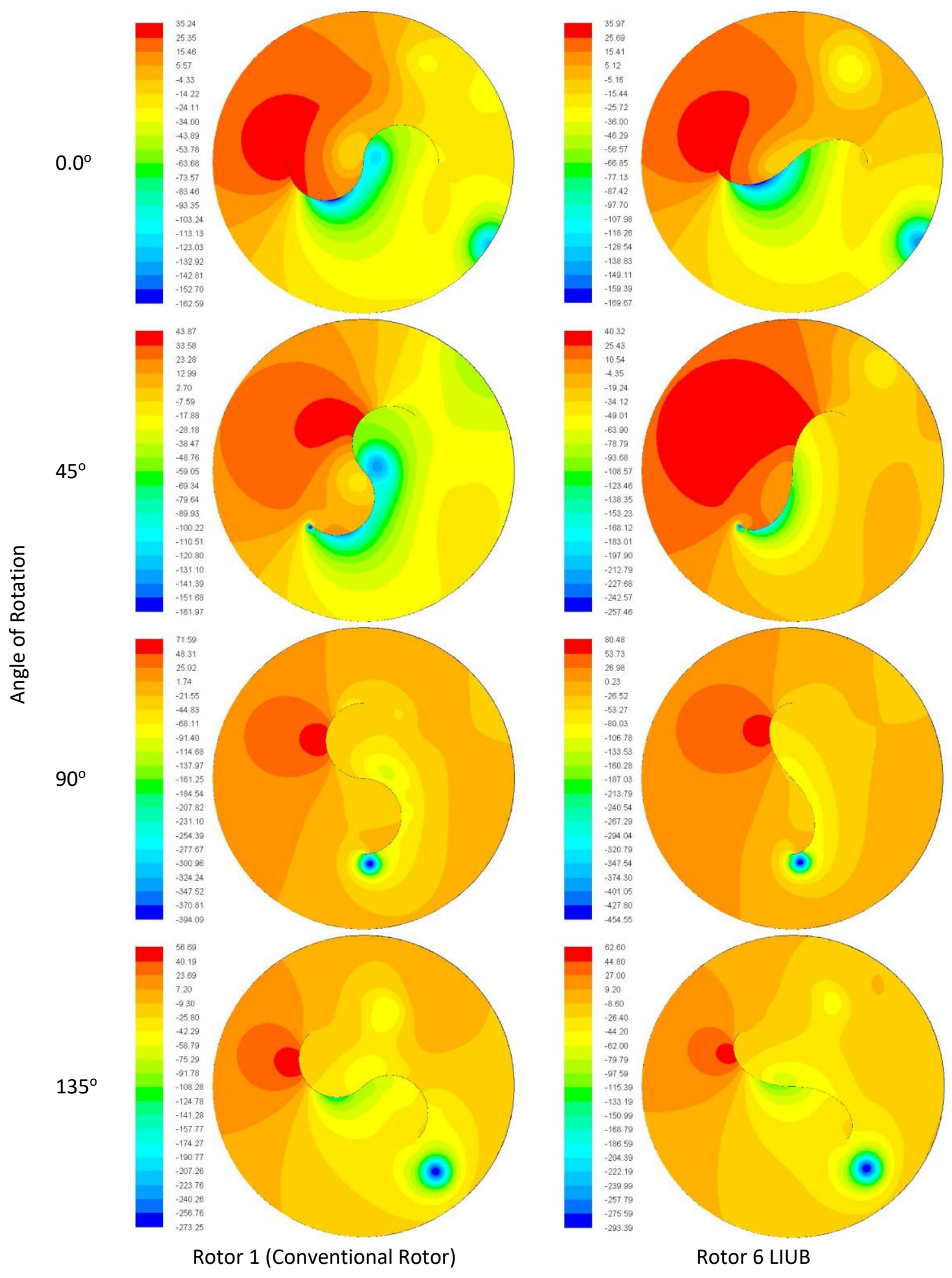

Fig. 12. Comparisons of static pressure distributions at $\lambda=0.9$ 
Comparisons of velocity contours for both the conventional blade and laterally inverted universal blade shape factor (LIB) are presented in Figure 13 at rotating angles of 0.0, 45, 90 and 135 degrees. Results displayed through Figure 13 were computationally obtained at wind speed of $8 \mathrm{~m} / \mathrm{sec}$ and a tip speed ratio $\lambda$ of 0.9 . Maximum values of velocity are coloured in red while minimum values are coloured in blue. As illustrated, regions of low pressure exhibit higher velocity magnitudes.

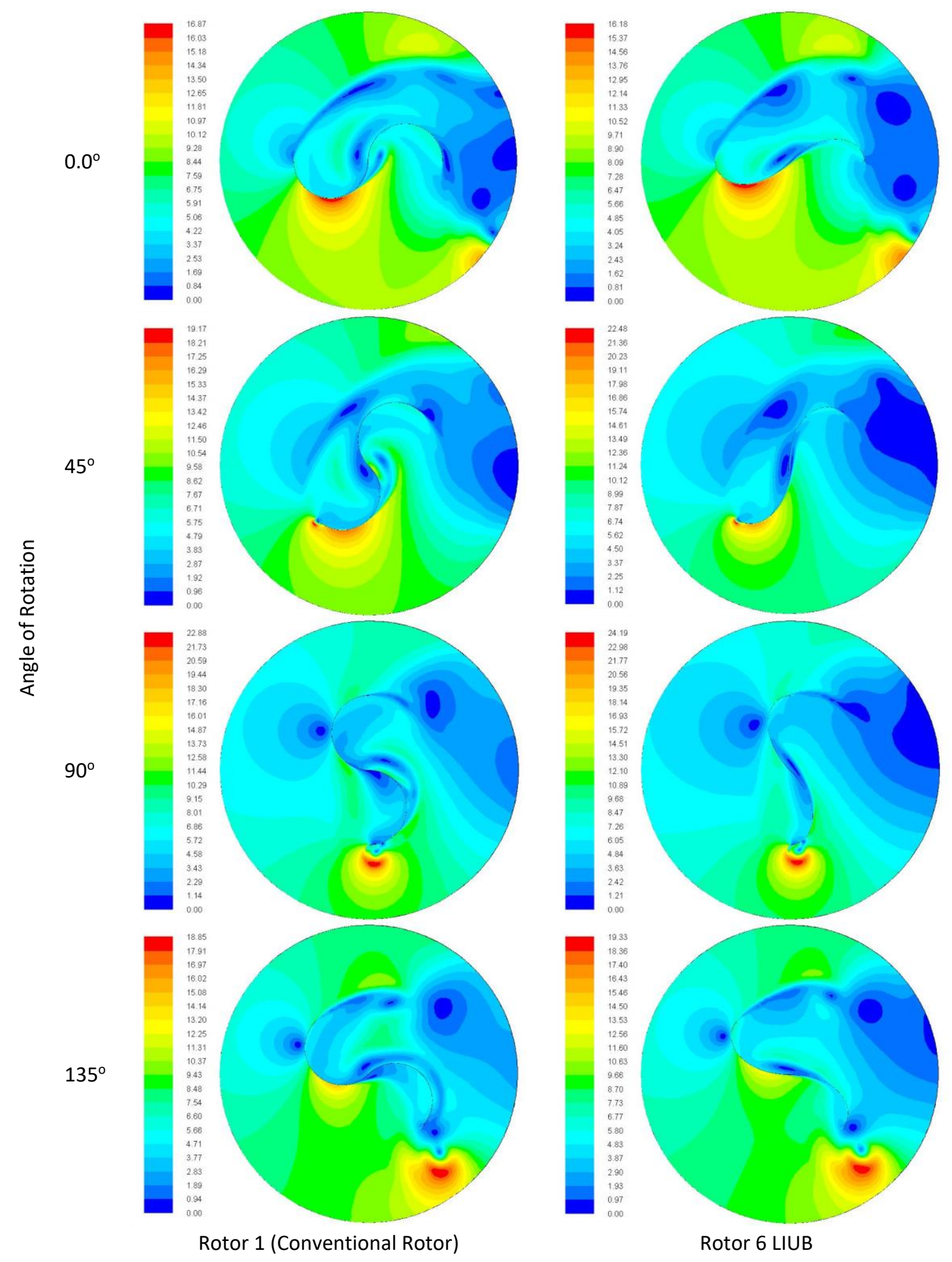

Fig. 13. Comparisons of velocity distributions at $\lambda=0.9$ 
It is apparent that regions of higher velocity magnitudes are located adjacent to the convex surface of the advancing blade (lower pressure regions). By increasing the degree of angle of rotation, this region is being detached from the leading edge of the advancing blade and becomes large in size particularly at rotational angle of 135 degrees. This demonstrates the unsteady characteristics of the wake behind the turbine rotor. Increasing the angle of rotations, moreover, is observed to be accompanied by an increase in the maximum value of velocity magnitudes till the angle of 90 degrees and then a decrease in that value. It is clear from Figure 13 that, the laterally inverted universal blade shape factor (LIUB) shows higher velocity magnitudes compared to the conventional blade particularly at rotational angles of 45, 90 and 135 degrees.

\section{Conclusions}

The current research presents a computational fluid dynamics investigation into the performance of Savonius vertical axis wind turbine having a modified blade shape. Modification made in Savonius blade geometry was based on universal consideration of blade shape factor concept. The set of points forming the blade geometry of the proposed modified Savonius blade was obtained according to the equation of point of tangency of blade arm with blade circular arc at various degrees of blade shape factor. Accordingly, each point in the proposed two-dimensional blade geometry was specified with a single value of blade shape factor. A relation that may define the blade geometry according to universal consideration of blade shape factor was suggested by fitting the set of points $(x, y)$ forming the blade profile.

The computational results of the modified blade (laterally inverted universal blade) revealed the possibility of running the Savonius turbine at higher tip speed ratios and consequently an increase in the turbine operating range is expected. Furthermore, results showed the potential of the modified rotor to improve the turbine output power as compared to the conventional rotor. The highest torque coefficient is increased by about $48 \%$ in case of laterally inverted universal blade shape factor design (LIUB) as compared to the conventional rotor. Besides, the power coefficient is modified by about $62 \%$ at a tip speed ratio of 1.1 .

\section{Acknowledgments}

The author wants to thank both Prof. N. I. Elkalashy, Menoufia University, and Dr. Mahmoud H. Nasef, Fayoum University, for their invaluable and sincere discussions regarding the topic of this work.

\section{References}

[1] Chaichana, T., and S. Thongdee. "Effect of blade number and angle on the characteristics of the savonius type wind turbine." In Journal of Physics: Conference Series, vol. 1380, no. 1, p. 012110. IOP Publishing, 2019. https://doi.org/10.1088/1742-6596/1380/1/012110

[2] Chan, Chun Man, H. L. Bai, and D. Q. He. "Blade shape optimization of the Savonius wind turbine using a genetic algorithm." Applied energy 213 (2018): 148-157. https://doi.org/10.1016/j.apenergy.2018.01.029

[3] Damak, A., Z. Driss, and M. S. Abid. "Experimental investigation of helical Savonius rotor with a twist of 180." Renewable Energy 52 (2013): 136-142. https://doi.org/10.1016/i.renene.2012.10.043

[4] El-Askary, W. A., Ahmed S. Saad, Ali M. AbdelSalam, and I. M. Sakr. "Investigating the performance of a twisted modified Savonius rotor." Journal of Wind Engineering and Industrial Aerodynamics 182 (2018): 344-355. https://doi.org/10.1016/i.jweia.2018.10.009

[5] Jeon, Keum Soo, Jun Ik Jeong, Jae-Kyung Pan, and Ki-Wahn Ryu. "Effects of end plates with various shapes and sizes on helical Savonius wind turbines." Renewable energy 79 (2015): $167-176$. https://doi.org/10.1016/i.renene.2014.11.035

[6] Kothe, Leonardo Brito, Sérgio Viçosa Möller, and Adriane Prisco Petry. "Numerical and experimental study of a helical Savonius wind turbine and a comparison with a two-stage Savonius turbine." Renewable Energy 148 (2020): 627-638. https://doi.org/10.1016/i.renene.2019.10.151 
[7] Lee, Jae-Hoon, Young-Tae Lee, and Hee-Chang Lim. "Effect of twist angle on the performance of Savonius wind turbine." Renewable Energy 89 (2016): 231-244. https://doi.org/10.1016/j.renene.2015.12.012

[8] Montelpare, Sergio, Valerio D'Alessandro, Andrea Zoppi, and Renato Ricci. "Experimental study on a modified Savonius wind rotor for street lighting systems. Analysis of external appendages and elements." Energy 144 (2018): 146-158. https://doi.org/10.1016/i.energy.2017.12.017

[9] Roy, Sukanta, and Ujjwal K. Saha. "Wind tunnel experiments of a newly developed two-bladed Savonius-style wind turbine." Applied Energy 137 (2015): 117-125. https://doi.org/10.1016/i.apenergy.2014.10.022

[10] Saad, Ahmed S., Ibrahim I. El-Sharkawy, Shinichi Ookawara, and Mahmoud Ahmed. "Performance enhancement of twisted-bladed Savonius vertical axis wind turbines." Energy Conversion and Management 209 (2020): 112673. https://doi.org/10.1016/j.enconman.2020.112673

[11] Saha, U. K. "Rajkumar. “On the performance analysis of Savonius rotor with twisted blades"." Ren. Energy 31 (2006): 1776-1788. https://doi.org/10.1016/i.renene.2005.08.030

[12] Tahani, Mojtaba, Ali Rabbani, Alibakhsh Kasaeian, Mehdi Mehrpooya, and Mojtaba Mirhosseini. "Design and numerical investigation of Savonius wind turbine with discharge flow directing capability." Energy 130 (2017): 327 338. https://doi.org/10.1016/i.energy.2017.04.125

[13] El-Askary, W. A., M. H. Nasef, A. A. Abdel-Hamid, and H. E. Gad. "Harvesting wind energy for improving performance of Savonius rotor." Journal of Wind Engineering and Industrial Aerodynamics 139 (2015): 8-15. https://doi.org/10.1016/i.jweia.2015.01.003

[14] Manganhar, Abdul Latif, Altaf Hussain Rajpar, Muhammad Ramzan Luhur, Saleem Raza Samo, and Mehtab Manganhar. "Performance analysis of a savonius vertical axis wind turbine integrated with wind accelerating and guiding rotor house." Renewable Energy 136 (2019): 512-520. https://doi.org/10.1016/i.renene.2018.12.124

[15] Mohamed, M. H., G. Janiga, E. Pap, and D. Thévenin. "Optimal blade shape of a modified Savonius turbine using an obstacle shielding the returning blade." Energy Conversion and Management 52, no. 1 (2011): $236-242$. https://doi.org/10.1016/i.enconman.2010.06.070

[16] Mohamed, M. H., G. Janiga, E. Pap, and D. Thévenin. "Optimization of Savonius turbines using an obstacle shielding the returning blade." Renewable Energy 35, no. $11 \quad$ (2010): 2618-2626. https://doi.org/10.1016/i.renene.2010.04.007

[17] Nimvari, Majid Eshagh, Hossein Fatahian, and Esmaeel Fatahian. "Performance improvement of a Savonius vertical axis wind turbine using a porous deflector." Energy Conversion and Management 220 (2020): 113062. https://doi.org/10.1016/i.enconman.2020.113062

[18] Qasemi, Keyhan, and Leila N. Azadani. "Optimization of the power output of a vertical axis wind turbine augmented with a flat plate deflector." Energy 202 (2020): 117745. https://doi.org/10.1016/j.energy.2020.117745

[19] Salleh, Mohd Badrul, Noorfazreena M. Kamaruddin, and Zulfaa Mohamed-Kassim. "The effects of deflector longitudinal position and height on the power performance of a conventional savonius turbine." Energy Conversion and Management 226 (2020): 113584. https://doi.org/10.1016/j.enconman.2020.113584

[20] Sewucipto, Sanjaya, and Triyogi Yuwono. "The Influence of Upstream Installation of D-53 ${ }^{\circ}$ Type Cylinder on the Performance of Savonius Turbine." Journal of Advanced Research in Experimental Fluid Mechanics and Heat Transfer 3, no. 1 (2021): 36-47.

[21] Altan, Burcin Deda, and Mehmet Atılgan. "An experimental and numerical study on the improvement of the performance of Savonius wind rotor." Energy Conversion and Management 49, no. 12 (2008): 3425-3432. https://doi.org/10.1016/i.expthermflusci.2008.06.006

[22] Deda, B., and M. Atilgan. "An experimental and numerical study on the improvement of the performance of Savonius win rotor." Energy Conversion and Management 49 (2008): $3425-3432$. https://doi.org/10.1016/i.enconman.2008.08.021

[23] Korprasertsak, Natapol, and Thananchai Leephakpreeda. "CFD-based power analysis on low speed vertical axis wind turbines with wind boosters." Energy Procedia $79 \quad$ (2015): 963-968. https://doi.org/10.1016/j.egypro.2015.11.594

[24] Korprasertsak, Natapol, and Thananchai Leephakpreeda. "Analysis and optimal design of wind boosters for Vertical Axis Wind Turbines at low wind speed." Journal of Wind Engineering and Industrial Aerodynamics 159 (2016): 9-18. https://doi.org/10.1016/j.jweia.2016.10.007

[25] Frikha, Sobhi, Zied Driss, Emna Ayadi, Zied Masmoudi, and Mohamed Salah Abid. "Numerical and experimental characterization of multi-stage Savonius rotors." Energy $114 \quad$ (2016): $382-404$. https://doi.org/10.1016/j.energy.2016.08.017

[26] Khandagale, Mr RM, and B. G. Marlapalle. "Design \& Analysis of Savonius VAWT for 50W Rated Power output." Int J Eng Res Gen Sci 5 (2017): 189-200. 
[27] Lates, Mihai, and Radu Velicu. "CFD analysis and theoretical modelling of multiblade small Savonius wind turbines." In Sustainable Energy in the Built Environment-Steps Towards nZEB, pp. 403-415. Springer, Cham, 2014. https://doi.org/10.1007/978-3-319-09707-7 30

[28] Wenehenubun, Frederikus, Andy Saputra, and Hadi Sutanto. "An experimental study on the performance of Savonius wind turbines related with the number of blades." Energy procedia 68 (2015): 297-304. https://doi.org/10.1016/i.egypro.2015.03.259

[29] Al-Ghriybah, Mohanad, Mohd Fadhli Zulkafli, Djamal Hissein Didane, and Sofian Mohd. "Performance of the Savonius Wind Rotor with Two Inner Blades at Low Tip Speed Ratio." CFD Letters 12, no. 3 (2020): 11-21. https://doi.org/10.37934/cfdl.12.3.1121

[30] Kurniawan, Yudi, Dominicus Danardono Dwi Prija Tjahjana, and Budi Santoso. "Experimental Study of Savonius Wind Turbine Performance with Blade Layer Addition." Journal of Advanced Research in Fluid Mechanics and Thermal Sciences 69, no. 1 (2020): 23-33. https://doi.org/10.37934/arfmts.69.1.2333

[31] Mahrous, Abdel-Fattah. "A Computational Fluid Dynamics Study of an Integrating Savonius-Darrieus Vertical Axis Wind Turbine." Journal of Advanced Research in Fluid Mechanics and Thermal Sciences 75, no. 1 (2020): 21-37. https://doi.org/10.37934/arfmts.75.1.2137

[32] He, D. Q., H. L. Bai, Chun Man Chan, and Kai Ming Li. "Performance-based Optimizations on Savonius-type Verticalaxis Wind Turbines using Genetic Algorithm." Energy Procedia 158 (2019): 643-648. https://doi.org/10.1016/i.egypro.2019.01.175

[33] Kamoji, M. A., Shireesh B. Kedare, and S. V. Prabhu. "Experimental investigations on single stage modified Savonius rotor." Applied Energy 86, no. 7-8 (2009): 1064-1073. https://doi.org/10.1016/i.apenergy.2008.09.019

[34] Moazam Sheikh, Haris, Zeeshan Shabbir, Hassan Ahmed, Muhammad Hamza Waseem, and Muhammad Zubair Sheikh. "Computational fluid dynamics analysis of a modified Savonius rotor and optimization using response surface methodology." Wind Engineering 41, no. 5 (2017): 285-296. https://doi.org/10.1177/0309524X17709732

[35] Zhang, Baoshou, Baowei Song, Zhaoyong Mao, Wenlong Tian, Boyang Li, and Bo Li. "A novel parametric modeling method and optimal design for Savonius wind turbines." Energies 10, no. 3 (2017): 301. https://doi.org/10.3390/en10030301

[36] Ansys, ANSYS FLUENT. "15.0 User's Guide, ANSYS." Inc., United States (2015).

[37] Nasef, M. H., W. A. El-Askary, A. A. Abdel-Hamid, and H. E. Gad. "Evaluation of Savonius rotor performance: Static and dynamic studies." Journal of Wind Engineering and Industrial Aerodynamics 123 (2013): 1-11. https://doi.org/10.1016/i.jweia.2013.09.009

[38] Rezaeiha, Abdolrahim, Hamid Montazeri, and Bert Blocken. "On the accuracy of turbulence models for CFD simulations of vertical axis wind turbines." Energy $180 \quad$ (2019): $838-857$. https://doi.org/10.1016/i.energy.2019.05.053

[39] Shaheen, Mohammed, and Shaaban Abdallah. "Development of efficient vertical axis wind turbine clustered farms." Renewable and Sustainable Energy Reviews $63 \quad$ (2016): $237-244$. https://doi.org/10.1016/i.rser.2016.05.062

[40] Didane, Djamal Hissein, Muhammad Amir Zafran Saipul Anuar, Mohd Faizal Mohideen Batcha, Kamil Abdullah, Mas Fawzi Mohd Ali, and Akmal Nizam Mohammed. "Simulation Study on the Performance of a Counter-rotating Savonius Vertical Axis Wind Turbine." CFD Letters 12, no. 4 (2020): 1-11. https://doi.org/10.37934/cfdl.12.4.111

[41] Mazlan, Mohamad Zahid, Fazila Mohd Zawawi, Teeab Tahzib, Kamarulafizam Ismail, and Syahrullail Samion. "Performance Analysis of Highway Wind Turbine Enhanced with Wind Guide Vanes Using the Taguchi Method." CFD Letters 13, no. 3 (2021): 25-42. https://doi.org/10.37934/cfdl.13.3.2542 